\title{
Unificação de termos na filologia: diálogo transdisciplinar e qualifıcação dos trabalhos
}

DOI: http://dx.doi.org/10.21165/el.v49i2.2712

\section{Maria de Fatima Nunes Madeira'}

\section{Resumo}

Filólogos de universidades brasileiras têm divulgado projetos de pesquisa cujos produtos - edições fidedignas de textos antigos e modernos - contribuem para a constituição de corpora variados para utilizações seguras por pesquisadores das mais diversas áreas do conhecimento. Dado este ressurgimento da filologia e das pesquisas em linguística histórica na década de 1990, eventos científicos nessa área tornaram-se importantes instrumentos de difusão desses trabalhos. Quanto mais a filologia se revela como curadoria filológica de textos, maior a conveniência do diálogo transdisciplinar entre filólogos, linguistas e historiadores. Este artigo propõe-se a discutir a diversidade de normas e nomenclaturas utilizadas para identificar os tipos fundamentais de edição, a partir de três manuais brasileiros de crítica textual - Cambraia (2005), Spina (1994) e Azevedo (1987) - e o papel de uma possível uniformização dessa terminologia filológica para qualificar as edições e para facilitar esse diálogo transdisciplinar.

Palavras-chave: filologia portuguesa; uniformização de terminologia; diálogo transdisciplinar; qualificação de estudos filológicos.

1 Universidade de São Paulo (USP), São Paulo, São Paulo, Brasil; fatima22.madeira@gmail.com; http://orcid.org/0000-0001-6141-0714 


\title{
Uniformization of terms in philology: trans-disciplinary dialogue and qualification of studies
}

\begin{abstract}
Philologists from Brazilian universities have been publishing research projects whose products - reliable editions of ancient and modern texts - contribute to the building of varied corpora for safe usage by researchers from a wide range of knowledge areas. Given this resurgence of philology and of researches in historical linguistics in the 1990s, scientific events in this area have become important instruments for disseminating these works. The more philology is revealed as a philological curatorship of texts, the greater the convenience of trans-disciplinary dialogue between philologists, linguists and historians. This article aims to discuss the diversity of norms and nomenclatures used for identifying the fundamental types of edition, from three Brazilian textbooks of textual criticism - Cambraia (2005), Spina (1994) and Azevedo (1987) - and the role of a possible uniformization of this philological terminology to qualify the editions and for furthering this trans-disciplinary dialogue.
\end{abstract}

Keywords: portuguese philology, uniformization of terminology, trans-disciplinary dialogue, qualification of philological studies.

\section{Introdução}

Mais de vinte e quatro séculos de existência documentada da Filologia e continuam os debates sobre a polissemia dessa ciência. O labor filológico, na acepção tanto ampla quanto restrita, segue a sua vocação de restaurar textos, entregando aos leitores contemporâneos, especializados ou não, edições que, sem a pretensão de serem definitivas ou perfeitas, têm atendido às expectativas do público-alvo específico principalmente de pesquisadores - das mais diversas áreas de estudo.

Embora reconhecidamente insuficiente, a produção filológica no Brasil foi intensificada a partir da década de 1990. "Apesar de ter aumentado bastante o número de estudiosos envolvidos com o problema da edição de textos, poucos foram os manuais de crítica textual publicados" (MEGALE; CAMBRAIA, 1999, p. 15). O primeiro manual universitário em língua portuguesa destinado ao ensino de crítica textual, no Brasil, escrito por Segismundo Spina, em 1977, foi reeditado em 1994: Introdução à edótica: crítica textual. Em 1987, Leodegário Amarante de Azevedo Filho publica sua Iniciação em crítica textual. E em 2005, é editada a Introdução à crítica textual, de César Nardelli Cambraia.

Comparar os três manuais, como metodologia, e descrever os diferentes usos feitos das nomenclaturas dos tipos de edição, salientando vantagens de uma possível uniformização 
de terminologia para a qualificação dos estudos científıcos filológicos e para intensificar o diálogo transdisciplinar: eis a proposta deste estudo.

\title{
A filologia, o texto e o público-alvo: curadoria do patrimônio cultural escrito
}

Todas as vezes que encontramos a palavra filologia numa publicação, imediatamente somos remetidos ao contexto em que ela está sendo empregada. A polissemia desse termo, que o acompanha desde o nascimento da filologia, na Grécia antiga, deixa transparecer que o labor filológico, lato ou stricto sensu, não cabe num significado único, numa disciplina única, ou numa atividade única. Para Ivo Castro (1995, p. 604):

\begin{abstract}
[...] somente o termo Filologia recobre ao mesmo tempo preocupações tão variadas como o estudo das técnicas e dos materiais que serviram à produção escrita de um texto, quer se trate de um autógrafo quer das suas cópias; o estudo das condições históricas (sociais, económicas, biográficas) que rodearam e influenciaram a produção de um texto e o estudo dos seus itinerários e lugares de pouso (coleções particulares, arquivos, bibliotecas); o estudo da sua conservação, mutilações e restauros; o estudo, no caso das cópias, do número, condições e protagonistas dos actos reprodutórios. Além de tudo isto, que tem a ver com o texto como objeto físico, e de um inevitável interesse pelas componentes gráficas, gramaticais, lexicais e discursivas do texto (ainda que se possa argumentar que elas pertencem a outras disciplinas), é também preocupação da Filologia, e possivelmente a mais visível de todas, estudar as técnicas de publicação moderna do texto e preparar as respectivas edições.
\end{abstract}

Nessa significação do termo filologia, encontramos a fonte de toda a atenção e de todo o esforço do filólogo e da filologia: o texto. A filologia concentra-se no texto, e parte dele para configurar o seu campo de atuação (SPINA, 1994).

Partindo da percepção de que cada texto requer um tratamento específico para ser entendido e publicado, a crítica textual pode ser compreendida como o trabalho de restituição do texto e, nesse caso, o significado do termo filologia pode se estreitar "a uma curadoria de texto histórico referente exclusivamente a textos escritos" (GUMBRECHT, 2003, p. 3, citado por FERREIRA, 2016, p. 234).

A aproximação do termo filologia à curadoria textual remete à etimologia da palavra curare, que em latim significa "tomar conta de" ou "administrar" (FERREIRA, 2016, p. 234). Se considerarmos que a responsabilidade de administrar um determinado documento escrito demanda do filólogo inumeráveis ações e decisões que permitem restituir esse texto, preservando-o e garantindo-Ihe maior longevidade, então é possível assentir que 
abordar a filologia como curadoria parece uma estratégia apropriada para se abranger todas as atividades envolvidas no labor filológico, sem o risco de deixar de citar sequer uma dessas atividades. Quando o filólogo cumpre a importante função de restaurar e transmitir o texto ao leitor, com a preocupação de deixar transparecer todas as etapas dessa restauração, ele está contemplando duas das perspectivas que garantem a eficácia de uma edição fidedigna: o próprio texto e o público-alvo.

\section{Transdisciplinaridade: uma característica intrínseca à crítica textual}

O filólogo-curador deve estar preparado para percorrer diferentes áreas do conhecimento, e se dispor a aperfeiçoar o diálogo entre as ciências envolvidas com o texto crítico: a Paleografia, a Codicologia, a Diplomática, a Bibliografia material, a Linguística, e também com a História, com a Arte, com a Literatura e com o Direito, dentre outras, dependendo do tipo de texto.

Embora a noção de transdisciplinaridade circule quase consensualmente entre os filólogos e os pesquisadores das mais diversas áreas, que, por um lado, reconhecem demandar conhecimentos alheios à sua especialidade, e por outro, se dispõem a compartilhar as suas competências e erudição em prol do desenvolvimento da ciência, essa prática não é ainda efetiva.

\section{A contribuição do Brasil à filologia portuguesa}

Em conferência no XLV Seminário do GEL - Grupo de Estudos Linguísticos do Estado de São Paulo², Megale (1998) já apresentava um panorama positivo da crítica textual moderna, constatando o rigor científico demonstrado tanto na pesquisa de documentos como nos critérios de estabelecimento de textos, resultado do trabalho conjunto entre arquivos, bibliotecas e projetos de pesquisa das universidades brasileiras.

Megale e Cambraia (1999) oportunamente escolheram os eventos científicos nacionais da área de filologia e língua portuguesa para mostrar os caminhos percorridos pela Filologia portuguesa no Brasil, de 1989 a 1999.

Nos vinte anos que se seguiram, os encontros nacionais e regionais continuam sendo parâmetros para acompanhar o desenvolvimento dos estudos de crítica textual, edição de textos e crítica genética, constituindo-se como espaços propícios para a interlocução entre pesquisadores de diversos estados do Brasil e também de outros países.

2 Conferência realizada na Universidade Estadual de Campinas, no dia 22 de maio de 1997. 
Significativa contribuição do Brasil à filologia portuguesa é atribuída aos três únicos manuais de crítica textual em língua portuguesa, publicados a partir de 1970, e escritos por brasileiros: Iniciação em crítica textual, por Leodegário Amarante de Azevedo Filho, de 1987; Introdução à edótica: crítica textual, por Segismundo Spina, $2^{\text {a }}$ edição revista e atualizada, de 1994 (1ª edição de 1977); e Introdução à crítica textual, por César Nardelli Cambraia, de 2005.

Esses manuais trazem - cada um abordando de maneira mais genérica ou mais aprofundada, de acordo com a ênfase dada pelo autor - capítulos sobre os conceitos e a história da crítica textual, sobre as ciências envolvidas na edição crítica, sobre os tipos e normas de edição, e sobre as operações para o estabelecimento e apresentação do texto crítico. Para o estudo deste artigo, atém-se, em cada manual, ao capítulo destinado à descrição dos diferentes tipos de edição de textos, que levam em conta o público-alvo, o grau de mediação do editor na fixação do texto e a existência de edições anteriores.

O atual engajamento acadêmico com a crítica textual, o encontro entre profissionais, projetos, universidades, arquivos e institutos de pesquisa, proporcionados pela internet e pelos eventos científicos realizados periodicamente, e as novas ferramentas tecnológicas disponíveis para a pesquisa e o tratamento de textos vêm abrindo novos caminhos e apresentando novos desafios para a filologia portuguesa. Um desses desafios consiste justamente na reflexão, pelos profissionais envolvidos na edição de textos críticos, sobre como a terminologia filológica vem sendo utilizada, como esse uso influencia a qualidade das edições e se pode ser verificado, com esse uso, o favorecimento da comunicação entre profissionais e entre disciplinas.

\section{A diversidade de termos e acepções}

Logo nas primeiras páginas de cada um dos três manuais, notamos a utilização distinta dos termos Reprodução, edição e publicação. Spina (1994), por exemplo, explica que editar um texto consiste em reproduzi-lo. Por isso, chama de reprodução a alguns tipos de edição, e a outros, de transcrição. Algumas vezes, usa reprodução e edição como sinônimos. Mas à reprodução do texto crítico, ele chama invariavelmente de edição crítica.

O professor Azevedo Filho utiliza somente o termo edição para nomear tanto a edição crítica como as demais edições.

Cambraia (2005) distingue edição de transcrição e de publicação. Para ele, publicação designa exclusivamente a composição tipográfica/eletrônica e impressão do texto. E a transcrição é apenas uma etapa da edição: 
Como se vê, não constituem sinônimos os termos edição e transcrição: editar significa realizar um conjunto complexo de operações das quais fazem parte não apenas a transcrição, mas também a proposição de conjecturas, a seleção de variantes (em uma edição crítica), a apresentação do texto, etc.

Mas é principalmente a diversidade da nomenclatura referente aos tipos de edição - que será detalhada na descrição dos respectivos capítulos de cada manual e no item Análise dos dados, adiante - que chama a atenção do leitor desses três manuais de crítica textual.

Como subsídio para cotejo da nomenclatura dos tipos de edição, foi consultado também o glossário de crítica textual da Universidade Nova de Lisboa, elaborado, em 2012, pelo Mestrado em Edição de Texto da Faculdade de Ciências Sociais e Humanas da Universidade Nova de Lisboa. Esse glossário aborda de forma simples e didática pouco mais de 200 verbetes relacionados ao universo da crítica textual, bem como da codicologia.

\section{A busca pela padronização da nomenclatura filológica}

Segundo Contreras (1994, p. 35), "as questões metodológicas se mostram hoje como primordiais na investigação e na didática de qualquer disciplina". Uma vez que a crítica textual lida com várias disciplinas e com profissionais de diferentes áreas, transmitindo aos leitores edições que revelam comparações e distinções, a aplicação de nomenclaturas precisas é essencial para que as informações sejam assimiladas tanto pelos profissionais como pelo público-alvo.

O professor Cambraia (2005) chama a atenção, em seu manual, para a necessidade de se uniformizar as normas de edição de textos em língua portuguesa. E comenta que a falta de padronização é proporcional à falta de diálogo entre os profissionais envolvidos nesse trabalho.

As preocupações de renomados paleógrafos que estudam padrões metodológicos para a descrição cada vez mais precisa dos tipos de escrita elucidam, por meio de publicações e de grupos de pesquisa, a necessidade de se padronizar normas e terminologias, a fim de se evitar ambiguidades e até mal-entendidos filológicos. Gumbert (2000, p. 11), por exemplo, adverte:

Enquanto nossos termos não estiverem acompanhados de definições claras e precisas, serão imprecisos, com uma zona cinza de incerteza a seu redor; nunca se saberá se o juízo emitido por alguém sobre um exemplo ligeiramente atípico será compartilhado por outro especialista e de igual maneira se estão falando do mesmo. 
A pesquisadora Cristina Sobral (2016, p. 214), envolvida em projeto de construção de um dicionário terminológico de crítica textual em português, a princípio destinado aos profissionais da crítica textual, salientando a necessidade de se padronizar a terminologia de crítica textual, esclarece:

\begin{abstract}
Com efeito, a instabilidade da terminologia de Crítica Textual em português, determinada por factores quer históricos quer geográficos, recomenda a produção de um instrumento de trabalho que possa promover um maior consenso entre utilizadores, facilitando a comunicação entre críticos textuais falantes de português, e também destes com a comunidade internacional, constituindo uma base para o estabelecimento de equivalências terminológicas com línguas estrangeiras, tanto mais desejável quanto é certo que os métodos desta disciplina se desenvolvem em aplicações cada vez mais abrangentes.
\end{abstract}

Por conseguinte, o cuidado com a uniformização das terminologias cria condições oportunas para se atingir tanto a precisão metodológica, indispensável para uma abordagem científica da crítica textual, como a comunicação e o entendimento entre os profissionais das diversas áreas do conhecimento; e, dessa forma, a qualificação das pesquisas científicas filológicas e de outras, delas decorrentes.

A seguir, uma breve apresentação do conteúdo geral de cada um dos manuais referidos neste estudo, e um resumo dos respectivos capítulos sobre os tipos de edições.

\title{
O manual de Segismundo Spina: Introdução à Edótica - crítica textual
}

O professor Spina nasceu em 1921, em Itajobi/SP e faleceu em 2012, em São Vicente/ SP, aos 91 anos. Foi professor da Faculdade de Letras da Universidade de São Paulo. A versão de 1994, objeto deste estudo, publicada em São Paulo pela Editora da Universidade de São Paulo em parceria com a Ars Poética Editora Ltda, com 165 páginas, está assim constituída:

Prefácio-resposta

Primeira Parte: Introdução

1. Conceituações prévias

2. A codicologia

3. Apontamentos paleográficos

4. Apontamentos diplomáticos 
Segunda Parte: A Edótica

1. A Edótica

2. O texto

3. A edição crítica

Quadro sinótico

Bibliografia

O fragmento a ser comparado com os outros dois manuais - item 2.4. As formas de reprodução de um texto - foi recortado da segunda parte do livro, capítulo 2: 0 texto. Em aproximadamente duas páginas (parte da p. 84, p. 85 e parte da p. 86 do livro), o autor descreve as formas de reproduzir um texto e os procedimentos que cada edição requer:

(01) Reprodução Mecânica - feita através de meios mecânicos, como a fotografia, a fototipia, a xerografia, que resultam no chamado fac-símile.

(02) Reprodução Diplomática - reprodução tipográfica do texto manuscrito, mantendo todas as suas características, sinais e lacunas, inclusive erros e passagens estropiadas, com a vantagem de oferecer uma interpretação paleográfica do texto.

(03) Transcrição diplomático-interpretativa - (ou semidiplomática) - representa um passo além da transcrição puramente diplomática, pois melhora o texto, dividindo palavras, desdobrando abreviaturas e atualizando a pontuação.

(04) Transcrição paleográfica - uma combinação de reprodução fac-similar com análise paleográfica, que descreve todas as alterações sofridas pelo texto, para se refletir sobre o estado original do documento.

Para introduzir a edição crítica, considerada a reprodução mais correta possível de um original, numa tentativa de alcançar com a maior fidelidade imaginável a última forma desejada pelo seu autor, Spina (1994) apresenta uma descrição prévia do texto crítico. As normas gerais para o estabelecimento crítico de um texto são apresentadas pelo autor num capítulo especial, com 68 páginas: A edição crítica. Apesar de ponderar sobre a impossibilidade de se aplicar normas absolutamente inflexíveis no estabelecimento de todos os textos, já que cada texto exige do filólogo técnicas específicas de trabalho, o professor Spina descreve, nesse capítulo, as operações de fixação do texto conforme o método lachmanniano, ou seja: recensio, estemática e emendatio. 
Este livro, constituído do compêndio de cursos ministrados pelo professor Spina na Faculdade de Letras da Universidade de São Paulo entre os anos de 1972 e 1975, tem por mérito ser o primeiro manual brasileiro de crítica textual, servindo de guia aos primeiros leitores, e de modelo aos autores dos futuros manuais.

\section{0 manual de Leodegário Amarante de Azevedo Filho: Iniciação em Crítica Textual}

O professor das Universidades Estadual e Federal do Rio de Janeiro nasceu em 1927, no Recife/PE, e faleceu em 2011, no Rio de Janeiro, aos 84 anos. O seu manual de crítica textual, publicado em 1987, no Rio de Janeiro, pela Presença Edições e pela Editora da Universidade de São Paulo, se constitui de 165 páginas, onde são abordados os seguintes temas:

1. Apresentação, por Antonio Houaiss

2. Introdução Geral

3. Conceito de Crítica Textual

4. Ciências Auxiliares e um Pouco de História

5. Edição Crítica e outras Edições

6. Etapas de uma Edição Crítica

7. Aplicação: Edição Crítica de Cinco Sonetos de Camões

8. Edição do Primeiro Soneto

9. Edição do Segundo Soneto

10. Edição do Terceiro Soneto

11. Edição do Quarto Soneto

12. Edição do Quinto Soneto

O capítulo Edição crítica e outras edições traz, nas páginas de número 29 a 35, o item Tipos de edição, aqui recortado para ser comparado com os demais manuais:

(01) Edição mecânica - consiste na reprodução fotográfica de um manuscrito ou mesmo de uma obra impressa, em forma de fac-símile.

(02) Edição diplomática - por meios tipográficos, reproduz exatamente a lição de um manuscrito. Faz-se anteceder, em geral, de estudo histórico, paleográfico ou codicológico. Presta valiosos serviços à própria elaboração de uma edição crítica. 
(03) Edição diplomático-interpretativa - pode recorrer a sinais de pontuação, atualizar ortografia, juntando e separando palavras. Já é uma espécie de edição crítica, por interpretar o texto.

(04) Edição crítica - segundo o autor, volta-se para obras com tradição textual divergente ou múltipla, devendo então procurar-se a unidade de lição, através de várias e especializadas operações. Ao capítulo seguinte - Etapas de uma edição crítica - o autor dedica vinte e seis páginas, onde os nomes das fases lachmannianas do estabelecimento do texto são apresentadas em latim: Recensio, collatio, eliminatio codicum descriptorum, stemma codicum, e emendatio. As oitenta e oito páginas seguintes do manual, que o diferenciam dos demais, foram muito bem aproveitadas com ricos exemplos práticos de edição crítica do próprio autor para cinco sonetos de Camões.

\section{O manual de César Nardelli Cambraia: Introdução à crítica textual}

O manual de crítica textual do jovem professor Cambraia, da Universidade Federal de Minas Gerais - pareceu-nos o mais completo dentre os três. E essa conclusão se dá não apenas pela constatação das cinquenta páginas a mais, em relação aos dois manuais que o antecederam. Com a prerrogativa de poder avaliar, do seu próprio ponto de vista, como professor, pesquisador e filólogo, a demanda de estudantes e pesquisadores universitários por um manual de crítica textual mais atualizado, o autor atingiu o seu propósito de apresentar, com linguagem simples, atual e objetiva, e de maneira mais aprofundada, assuntos tradicionais e também os mais recentes, como a crítica genética e a edição de textos na era digital. O livro, publicado em 2005, em São Paulo, pela editora Martins Fontes, está dividido em oito partes, apresentadas a seguir, sem os subitens:

\section{Prefácio}

Lista de Abreviaturas

1. Introdução

2. Breve histórico da crítica textual

3. A transmissão dos textos

4. Tipos de edição

5. Normas de edição

6. Edição crítica

7. Crítica textual \& informática

8. Crítica textual \& ensino

Referências bibliográfıcas 
No capítulo Tipos de edição, recortado para este estudo, o autor diferencia os tipos gerais dos tipos fundamentais de edição, de acordo com suas categorias. Para Cambraia, os tipos fundamentais de edição se baseiam na forma de estabelecimento do texto e podem ser divididas em monotestemunhais e politestemunhais. 0 autor relaciona as edições monotestemunhais em ordem crescente do grau de mediação realizada pelo crítico textual na fixação da forma do texto:

(01) Edição fac-similar - (ou fac-símile, ou fac-similada, ou mecânica) - com grau zero de mediação, apenas é reproduzida a imagem de um testemunho através de meios mecânicos como fotografia, xerografia, escanerização, etc.

(02) Edição diplomática - com grau baixo de mediação, faz-se uma transcrição conservadora de todos os elementos presentes no modelo.

(03) Edição Paleográfica - (ou semidiplomática, ou paradiplomática, ou diplomáticointerpretativa) - dando um passo a mais em termos de mediação, o editor desenvolve abreviaturas, insere ou suprime elementos por conjectura, sempre assinalando essas operações na reprodução.

(04 Edição interpretativa - com grau máximo de mediação admissível, neste caso o texto passa por um forte processo de uniformização gráfica, e as conjecturas vão além de falhas óbvias, para aproximar o texto do que teria sido sua forma genuína.

A edição crítica e a edição genética fazem parte do grupo de edições definidas por Cambraia como politestemunhais. O escritor explica que a edição crítica confronta os testemunhos, geralmente apógrafos, no processo de estabelecimento do texto, para se reconstituir a última forma que seu autor Ihe havia dado. E reserva um capítulo exclusivo para esse tipo de edição, com quarenta e uma páginas para tratar tanto das operações do estabelecimento do texto, utilizando os termos do método lachmanniano em português (Recensão - Localização e coleta de fontes; colação; estemática; e Reconstituição - por testemunhos; por conjectura), como da proposta de modelo básico de apresentação do texto crítico. A crítica genética não será analisada neste estudo, por ter sido descrita somente neste manual e no glossário português.

O professor Cambraia referencia, em seu livro, os nomes das edições utilizados nos demais manuais e também no glossário de crítica textual da Universidade Nova de Lisboa, possibilitando, assim, ao leitor, identificar e relacionar os diversos tipos de edições em cada um dos manuais. Por exemplo, quando descreve a edição fac-similar, o autor cita os demais nomes como essa edição pode ser identificada: fac-símile, ou fac-similada (no 
glossário), ou mecânica (nos manuais de Spina e Azevedo). A edição paleográfica é também conhecida como semidiplomática (Spina), paradiplomática (glossário), ou diplomáticointerpretativa (Spina e Azevedo).

\section{A análise dos dados}

A amostragem da variedade de terminologias para os tipos de edição expostas nos manuais e no glossário foi agrupada em quadros, para uma melhor visualização.

Quadro 1. Edição Fac-similar

\begin{tabular}{|l|l|l|}
\hline \multicolumn{1}{|c|}{ Edição } & \multicolumn{1}{|c|}{ Manual } & \multicolumn{1}{c|}{ Procedimentos } \\
\hline Mecânica & Spina & Fac-símile gerado por procedimentos mecânicos \\
\hline Mecânica & Azevedo & Fac-símile gerado por reprodução fotográfica \\
\hline Fac-similar & Cambraia & Fac-símile gerado por meios mecânicos \\
\hline Fac-similada & Glossário & Fac-símile gerado por meios mecânicos \\
\hline
\end{tabular}

Fonte: Elaboração própria

Segundo Sobral (2016, p. 214), "a terminologia, além de um instrumento prático, é um instrumento epistemológico que conduz a um posicionamento doutrinário, na medida em que uma terminologia reclama coerência e interrelacionalidade entre os diversos verbetes".

Essa declaração pode ser exemplificada com o uso atualmente preferencial do nome facsimilar. Por remeterem à finalidade da edição, revelando de imediato o resultado esperado para a apresentação do testemunho (do latim fac simile = faz igual), os nomes fac-similar/ fac-similada/fac-símile têm sido adotados de maneira notável pelos profissionais da crítica textual, inclusive pelos estrangeiros.

É verdade também que algumas dessas escolhas são baseadas no "modo particular como cada crítico textual entrou em contato com a disciplina ao longo do seu percurso científico, isto é, como recebeu a sua formação, que influências sofreu, em que 'escola' se reconhece" (SOBRAL, 2016, p. 207). Por isso, algumas vezes ainda encontramos o termo mecânica.

Já nos quadros a seguir, observa-se que a unanimidade no uso das terminologias diplomática e crítica - é proporcional à uniformidade dos procedimentos especificados pelos autores dos manuais e do glossário para cada um desses tipos de edição. 
Quadro 2. Edição Diplomática

\begin{tabular}{|l|l|l|}
\hline \multicolumn{1}{|c|}{ Edição } & \multicolumn{1}{|c|}{ Manual } & \multicolumn{1}{c|}{ Procedimentos } \\
\hline Diplomática & Spina & $\begin{array}{l}\text { reprodução tipográfica do texto manuscrito, mantendo todas } \\
\text { as suas características, sinais e lacunas. }\end{array}$ \\
\hline Diplomática & Azevedo & $\begin{array}{l}\text { por meios tipográficos, reprodução exata da lição de um } \\
\text { manuscrito. }\end{array}$ \\
\hline Diplomática & Cambraia & $\begin{array}{l}\text { transcrição conservadora de todos os elementos presentes no } \\
\text { modelo. }\end{array}$ \\
\hline Diplomática & Glossário & $\begin{array}{l}\text { reprodução tipográfica rigorosa da lição de um testemunho, } \\
\text { conservando todas as suas características. }\end{array}$ \\
\hline
\end{tabular}

Fonte: Elaboração própria

Quadro 3. Edição Crítica

\begin{tabular}{|l|l|l|}
\hline \multicolumn{1}{|c|}{ Edição } & \multicolumn{1}{|c|}{ Manual } & \multicolumn{1}{c|}{ Procedimentos } \\
\hline Crítica & Spina & $\begin{array}{l}\text { Reprodução mais correta possível de um original. } \\
\text { Objetivo: alcançar com a maior fidelidade a última forma } \\
\text { desejada pelo autor. }\end{array}$ \\
\hline Crítica & Azevedo & $\begin{array}{l}\text { Obras com tradição textual divergente ou múltipla. } \\
\text { Objetivo: procurar a unidade de lição, através de várias e } \\
\text { especializadas operações. }\end{array}$ \\
\hline Crítica & Cambraia & $\begin{array}{l}\text { Contraste de mais de um testemunho, no processo de } \\
\text { estabelecimento do texto. } \\
\text { Objetivo: reconstituir a última forma dada pelo seu autor. }\end{array}$ \\
\hline Crítica & Glossário & $\begin{array}{l}\text { Reprodução do texto do autógrafo ou do texto criticamente } \\
\text { definido como mais próximo do original. }\end{array}$ \\
\hline
\end{tabular}

Fonte: Elaboração própria

O nome diplomática define de forma precisa e indubitável a edição que interpreta e reproduz fielmente o original, o diploma. Da mesma forma, o termo crítica define a edição que se caracteriza pelo confronto de mais de um testemunho com o objetivo de reconstituir a última forma dada pelo seu autor ao texto crítico. Essa terminologia cumpre, portanto, a funcionalidade exigida para que um termo seja compreendido, adotado e utilizado de forma abrangente, facilitando a comunicação transdisciplinar, inclusive estabelecendo equivalência com a terminologia internacional: diplomatique e critique (francês); diplomatische e kritische (alemão); diplomatica e critica (italiano); diplomatic e critical (inglês); diplomática e crítica (espanhol). 
Um fenômeno interessante é o que se observa no quadro a seguir, com o uso da terminologia para uma edição que se encontra na fase entre a diplomática e a crítica. O termo semidiplomática é apresentado somente por Cambraia e por Spina, como terminologia alternativa, e não como verbete principal. Os demais autores sequer citam essa nomenclatura. Mesmo assim, é esse o termo preferencialmente adotado e reconhecido para identificar esse tipo de edição na maioria dos trabalhos acadêmicos na Universidade de São Paulo e também em universidades de outras regiões do Brasil, quando se pesquisam teses e dissertações acadêmicas.

Quadro 4. Edição Semidiplomática

\begin{tabular}{|c|c|c|c|}
\hline \multirow{6}{*}{ 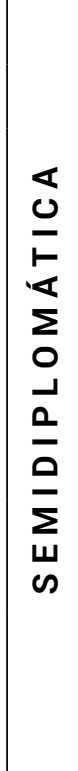 } & Edição & Procedimentos & Manual \\
\hline & Paradiplomática & desenvolvimento das abreviaturas. & Glossário \\
\hline & Interpretativa [1] & $\begin{array}{l}\text { correção dos erros por conjectura } \\
\text { registro em aparato de todas as } \\
\text { intervenções. }\end{array}$ & Glossário \\
\hline & Paleográfica & $\begin{array}{l}\text { desdobramento abreviaturas } \\
\text { inserção ou supressão de elementos por } \\
\text { conjectura } \\
\text { indicação dessas operações na reprodução }\end{array}$ & Cambraia \\
\hline & Diplomático-interpretativa & $\begin{array}{l}\text { divisão de palavras } \\
\text { pontuação }\end{array}$ & Azevedo \\
\hline & Diplomático-interpretativa & $\begin{array}{l}\text { desdobramento de abreviaturas } \\
\text { divisão de palavras } \\
\text { pontuação }\end{array}$ & Spina \\
\hline
\end{tabular}

Fonte: Elaboração própria

Essa preferência pelo termo semidiplomática pode ser entendida a partir da seguinte explicação de Sobral (2016, p. 214): "uma palavra só será termo se o seu uso, proposto ou praticado mesmo que repetidamente por uma pessoa, for acolhido e adoptado por outras que reconhecem a sua funcionalidade operativa na disciplina".

O prefixo semi, do latim, denota a ideia de metade, de quase. O termo semidiplomática estabelece uma correspondência com o termo diplomática, na medida em que representa uma edição quase diplomática. Uma edição com o objetivo de tornar o texto acessível a um público um pouco mais amplo que o da edição diplomática, sem, contudo, descuidar de suas propriedades conservadoras, imprescindíveis para pesquisas sobre a história da língua portuguesa, por exemplo. Não é difícil deduzir o motivo pelo qual os críticos textuais 
elegeram essa nomenclatura: trata-se de uma terminologia que promove consenso entre os utilizadores e diálogo entre pesquisadores de diversas disciplinas e nacionalidades.

O grau de conservadorismo que cada autor atribui a esse tipo de edição pode ser observado nas operações indicadas para a transcrição do texto. As diferenças entre as intervenções parecem pequenas, entretanto, expõem variações significativas. O que o manual de Cambraia indica como procedimentos plausíveis para uma edição paleográfica (ou semidiplomática), o glossário divide em duas etapas, ou seja, em dois tipos de edições: a paradiplomática e a interpretativa (fase 1$)^{3}$.

Os procedimentos indicados pelos manuais de Spina e Azevedo para a edição diplomáticointerpretativa - pontuação e intervenção na divisão de palavras (juntar ou separar, de acordo com a ortografia atual) -, já representam um grau mais elevado na mediação do texto, que Cambraia admite apenas na edição interpretativa de seu manual. O glossário também descreve essa edição, classificando-a como interpretativa (fase 2).

Embora coerente, se tomarmos em conta o significado isolado de cada uma das palavras que compõem o termo diplomático-interpretativa, ou seja: uma edição diplomática com algumas operações interpretativas; e se valendo desse nome por ser o único tipo de edição entre a diplomática e a crítica, nos manuais de Azevedo e Spina, a aproximação dos dois nomes expõe certa incompatibilidade, pois, conforme pontua Rita Marquilhas, no e-dicionário de termos literários: a marca que defıne a edição diplomática é justamente "a renúncia a qualquer esforço interpretativo ou reconstrutivo" (CEIA, 2009).

Além disso, Spina e Azevedo não citam a necessidade de se informar, nesse tipo de edição, as etapas da restauração do texto, procedimento essencial para a eficácia de uma edição fidedigna.

\section{Considerações finais}

Os trabalhos filológicos realizados em mais de dois mil anos, desde a Biblioteca de Alexandria, renderam edições que vêm contribuindo para a recuperação de variado e rico patrimônio cultural escrito, para a transmissão e preservação desse patrimônio, para a transformação desses textos em fontes de pesquisa e de estudos para as mais diversas áreas do conhecimento (CAMBRAIA, 2005).

3 O glossário distingue ainda duas fases para a edição interpretativa: [1] edição crítica de um texto de testemunho único; nesta situação, o editor transcreve o texto, corrige os erros por conjectura (emendatio ope ingenii) e regista em aparato todas as suas intervenções. [2] Edição de um texto de testemunho único ou de um determinado testemunho isolado de uma tradição, destinada a um público de não-especialistas: para além da transcrição e da correcção de erros, o editor actualiza a ortografia e elabora notas explicativas de carácter geral. 
Não é de se estranhar que algumas dessas edições chegassem sem a esperada fidedignidade - não por má fé, mas pelo impulso de editores para entregar à posteridade textos legíveis. Pois foram justamente essas experiências editoriais que levaram ao reconhecimento, pela crítica textual moderna, da imprescindibilidade de métodos rigorosos e claros para o estabelecimento do texto. A partir dessa constatação, a produção bibliográfica teórica baseada na investigação por métodos cada vez mais rigorosos e confiáveis para a reconstituição objetiva de um original perdido enriqueceu os estudos filológicos e trouxe cientificismo à crítica textual contemporânea.

Recentemente, a preocupação com o rigor atingiu também a bibliografia teórica sobre a precisão das terminologias, cujos critérios de utilização são considerados essenciais para manter tanto o caráter científico como o caráter transdisciplinar da filologia portuguesa.

Para colaborar com essa reflexão, as análises apresentadas neste artigo lançaram luz sobre a terminologia atualmente aplicada aos tipos de edições filológicas. Observou-se, assim: a diversidade de termos utilizados para um mesmo tipo de edição e a influência da funcionalidade dos termos para a sua adoção pelos críticos textuais.

Podemos ainda considerar, a partir desta pesquisa - a qual certamente requer continuidade e aprofundamento - que a comunicabilidade do termo e a sua correspondência com os procedimentos adotados em cada tipo de edição (afastadas possíveis ambiguidades, ou seja, uma terminologia coesa, distinta e funcional) são características que favorecem o uso, o processo de unificação terminológica e, consequentemente, o diálogo transdisciplinar, inclusive entre profissionais de diferentes nacionalidades.

Ao leitor empático à argumentação deste artigo, que esteja considerando a viabilidade de aplicação desta ousada, mas não inédita proposta de unificação de termos filológicos, e se perguntando como, quando e onde ela poderia ser colocada em prática, transmito um excerto de Ivo Castro (2003, p. 18), que trata de assunto similar, ou seja, de uma proposta de normatização linguística: a uma colega que lhe perguntou "se afinal as questões de norma não pertenciam às competências da Academia das Ciências, a resposta que subtilmente suscitou só podia ser que a competência deve estar onde se encontra a ciência. Ou seja, no ambiente universitário.".

\section{REFERÊNCIAS}

AZEVEDO FILHO, L. A. Iniciação em Crítica Textual. Rio de Janeiro: Presença Edições; São Paulo: Editora da Universidade de São Paulo, 1987.

CAMBRAIA, C. N. Introdução à crítica textual. São Paulo: Martins Fontes; 2005. 
CASTRO, I. Filologia. Biblos: Enciclopédia Verbo das Literaturas de Língua Portuguesa, Lisboa: Verbo, v. 2, 1995.

CASTRO, I. O linguista e a fixação da norma. In: ENCONTRO NACIONAL DA ASSOCIAÇÃO PORTUGUESA DE LINGUÍSTICA, 18, 2002, Porto. Lisboa: APL, 2003, p. 11-24.

CEIA, C. E-Dicionário de Termos Literários: gênese e desenvolvimento. Lisboa: Universidade Nova de Lisboa, Centre for English, Translation and Anglo-Portuguese Studies, 2009. Disponível em: http://edtl.fcsh.unl.pt. Acesso em: 17 set. 2019.

CONTRERAS, L. N. Manual de Paleografia. Madrid: Cátedra, 1994.

FERREIRA, P. T. Filologia como curadoria: o caso Pessoa. Filol. Linguíst. Port., São Paulo, v. 18, n. 2, p. 231-262, ago./dez. 2016. Disponível em: http://dx.doi.org/10.11606/ issn.2176-9419.v18i2p231-262. Acesso em: 28 set. 2019.

GUMBERT, J. P. Letras y coordenadas: enfoque cartesiano a una disciplina humana. Signo: Revista de Historia de la Cultura Escrita, Universidade de Alcalá, v. 7, p. 9-28, 2000.

GUMBRECHT, H. U. The Powers of Philology: Dynamics of Textual Scholarship. Urbana e Chicago: University of Illinois Press, 2003.

MEGALE, H. Pesquisa filológica: os trabalhos da tradição e os novos trabalhos em língua portuguesa. In: Anais. São José do Rio Preto: UNESP/GEL, 1998.

MEGALE, H.; CAMBRAIA, C. N. Filologia portuguesa no Brasil. D.E.L.T.A, São Paulo, v. 15, n. 3, p. 1-22, 1999. Disponível em: https://revistas.pucsp.br/delta/article/view/40264. Acesso em: 28 set. 2019.

REINACH, S. Manuel de Philologie Classique. Paris: Librairie Hachette, 1883.

RONCAGLIA, A. Principi e applicazioni di critica testuale. Roma: Bulzoni, 1975.

SILVA, M. de C. e. A palavra filologia e as suas diversas acepções: os problemas da polissemia. Revista Confluência, Rio de Janeiro, n. 23, p. 53-70, 2002. 
SOBRAL, C. Estemática em português: termos, história, conceitos. Estud. Lingüíst. Galega, v. 8, p. 205-227, 2016. Disponível em: http://dx.doi.org/10.15304/elg.8.2759. Acesso em: 28 set. 2019.

SPINA, S. Introdução à Edótica: Crítica Textual. 2. ed. rev. atual. São Paulo: Ars Poética; Editora da Universidade de São Paulo; 1994. 